\title{
Монтмориллонитовая глина, пилларированная алюминием, для селективной адсорбции аргона из его смеси с кислородом
}

\author{
Иванова Е.Н., Бурмистрова Н.Н., Алехина М.Б., Дудоладов А.О. \\ Российский химико-технологический университет им. Д. И. Менделеева, Москва
}

Поступила в редакцию 22.11.2017 г.

\begin{abstract}
Природная монтмориллонитовая глина была пилларирована путем катионного обмена с растворами основных солей алюминия и последующим прокаливанием. Исследовано влияние температуры прокаливания в диапазоне $300-600^{\circ} \mathrm{C}$ на текстурные характеристики и адсорбционную емкость адсорбентов Al-PILC по парам воды, аргону и кислороду. Показано, что повышение температуры прокаливания в исследованном диапазоне приводит к гидрофобизации поверхности адсорбентов. Наибольшее значение коэффициента разделения смеси аргон-кислород наблюдали у образца Al-PILC, прокаленного при $550^{\circ} \mathrm{C}$.
\end{abstract}

Ключевые слова: монтмориллонитовая глина, пилларирование, адсорбция, кислород, аргон.

\section{Al-pillared montmorillonite clay for selective adsorption of argon from its mixture with oxygen}

\author{
Ivanova E.N., Burmistrova N.N., Alekhina M.B., Dudoladov A.O. \\ D.I. Mendeleyev University of Chemical Technology of Russia, Moscow
}

The purpose of the study was to investigate the influence of the calcination temperature of the montmorillonite clay, which is pylarized with aluminum, on its adsorption properties in terms of water, argon and oxygen. Clay modification conditions: $\mathrm{Al}^{3+} / \mathrm{OH}$ ratio $1: 2.4$, ion exchange temperature $25^{\circ} \mathrm{C}$, drying temperature $85^{\circ} \mathrm{C}$, calcination temperature $300-600^{\circ} \mathrm{C}$. Tableting of the samples was carried out without a binder by the dry molding method using a hydraulic press at a pressure of $780 \mathrm{~kg}$. Calcination was carried out in an air atmosphere at $300-600^{\circ} \mathrm{C}$. The elemental composition of the obtained samples was determined by the X-ray fluorescent method. To determine the structural and energy characteristics of the samples of the pylarized clay, nitrogen adsorption isotherms were removed at $77 \mathrm{~K}$. For the thermogravimetric analysis, the samples of the initial clay and Al-PILC samples calcined after molding at $300-600^{\circ} \mathrm{C}$ were pre-saturated in a desiccator at room temperature by water vapor up to state of equilibrium. The equilibrium capacities of the samples for oxygen and argon were determined on the basis of the kinetic curves of adsorption of these gases at $25^{\circ} \mathrm{C}$ and atmospheric pressure, taken with a volumetric unit. The relative error in the measurement was $5 \%$. The values of the separation coefficient were calculated as the ratio of the equilibrium capacities of argon and oxygen.

It was shown that in a wide range of changes in the values of the calcination temperature, the separation coefficient of the argon-oxygen mixture varies slightly. Adsorption of oxygen is maximal in samples calcined at $350-500^{\circ} \mathrm{C}$. With a further increase in the calcination temperature, the adsorption of oxygen decreases somewhat. The greatest value of the separation factor of the argon-oxygen mixture, equal to 1.5, was observed in the Al-PILC (No. 6) sample calcined at $550^{\circ} \mathrm{C}$.

Keywords: montmorillonite clay, pillaring, adsorption, oxygen, argon. 


\section{Введение}

Одним из методов модифицирования природных слоистых силикатов с целью придания им желаемых свойств для последующего использования их в качестве адсорбентов или катализаторов является метод пилларирования. Наибольшее распространение получили пиллар-глины или PILC-сорбенты (pillared interlayer clayсорбенты) на основе монтмориллонита и основных солей алюминия [1].

Монтмориллонит - это основной глинистый минерал в группе бентонитов со структурой 2:1 [1-3]. Структура представляет собой отдельные пакеты, связанные между собой. Пакет кристаллической решетки состоит из двух тетраэдрических кремнекислородных сеток, между которыми одна октаэдрическая Al- или Mgсодержащая кислородно-гидроксильная сетка. Все сетки пакета имеют примерно равные размеры и образуют связанные слои. Элементарная ячейка монтмориллонита включает 20 атомов кислорода и четыре гидроксильные группы и состоит из восьми кремнийкислородных тетраэдров и четырех алюминий-содержащих октаэдров.

Структура пор монтмориллонита образована первичными щелевидными порами переменной ширины в пластинчатых частицах и вторичными, представляющими собой пространство между ними. В межпакетном пространстве располагаются обменные катионы $\left(\mathrm{Na}^{+}, \mathrm{K}^{+}\right.$или $\left.\mathrm{Ca}^{2+}\right)$, а также молекулы воды, которые предотвращают слипание слоев [2,3]. Межплоскостное (межпакетное) расстояние в монтмориллоните не является жестким и в зависимости от содержания воды в глине и состава обменных катионов может варьироваться от 0,96 нм в сухом состоянии до 14 нм во влажном [3].

Кристаллическая решетка монтмориллонита изначально электрически неуравновешенна, кроме того, в ней всегда происходят изоморфные замещения: в тетраэдрической сетке $\mathrm{Si}$ замещается на $\mathrm{Al}$; в октаэдрической сетке $\mathrm{Al}$ - на $\mathrm{Mg}, \mathrm{Fe}, \mathrm{Zn}$, $\mathrm{Ni}, \mathrm{Li}$ [3-5]. Изоморфные замещения, в свою очередь, приводят к возникновению избыточного отрицательного заряда, сосредоточенного в октаэдрических слоях, распределенного по всем атомам кислорода.

На расстояние между отдельными пакетами влияют количество ОН-групп на базальной поверхности слоев, тип и количества обменных катионов, размер вклинивающихся молекул веществ. При отсутствии обменных ионов введение воды в межпакетное пространство способствует возрастанию «набухаемости» монтмориллонитовой глины при увлажнении [6]. При наличии обменных катионов их тип является определяющим фактором, влияющим на «набухаемость», так, катионы $\mathrm{Na}^{+}$и $\mathrm{K}^{+}$ обеспечивают переход глины в состояние неограниченного разбухания, катионы $\mathrm{Ca}^{2+}$ и $\mathrm{Mg}^{2+}$ ограничивают способность монтмориллонита к поглощению влаги. Обменные катионы щелочных и щелочноземельных металлов способны эквивалентно и обратимо замещаться на катионы из модифицирующих растворов. Другим источником обменных центров являются слабокислые гидроксильные группы (Si-OH) и основные $(\mathrm{Al}-\mathrm{OH})$ на боковых гранях и ребрах, которые в зависимости от $\mathrm{pH}$ участвуют в ионном обмене.

Обменные катионы в межпакетном пространстве, одинарные и парные гидроксильные группы при атомах кремния, ненасыщенные парные гидроксилы при атомах алюминия, ненасыщенные атомы кислорода на границе тетраэдрических и октаэдрических структурных элементов и сорбированные молекулы воды выступают в роли активных центров, что способствует применению монтмориллонитовых глин в качестве адсорбентов и катализаторов [3,6].

Процесс введения дополнительных групп и элементов в структуру материала называется интеркалированием. Этот метод эффективно используется для модифи- 
цирования текстурных характеристик глин, создания в них развитой сети микропор, придания им термостабильности. Результатом интеркалирования является возникновение новых структур, содержащих помимо слоев исходной глины, слои, состоящие из введенных катионов или веществ [7-11]. Суть метода пилларирования (частный случай интеркалирования) заключается в обмене межслоевых катионов глины на полигидроксокатионы различной природы $\left(\mathrm{Al}^{3+}, \mathrm{Fe}^{3+}, \mathrm{Ti}^{4+}, \mathrm{Zr}^{4+}\right.$ и др) [1,7-12]. Во время прокаливания при повышенных температурах полигидроксокатионы преобразуются в твердые оксидные столбцы, при этом высвобождаются протоны, которые мигрируют в силикатных слоях, становясь недоступными для ионного обмена $[7,13,14]$.

О качестве пилларированных материалов можно судить по их термической стабильности, удельной поверхности и величине межпакетного расстояния $\mathrm{d}_{001}$. В работах $[7,14,15-17]$ получены значения $\mathrm{d}_{001}$ для пилларированных глин, прокаленных при 100-550 ${ }^{\circ} \mathrm{C}$ (1.8-1.9 нм), а также определены зависимости удельной поверхности и объемов пор от температуры прокаливания. Авторы сделали вывод, что термическая стабильность материала, которую они определили, как неизменность величины $\mathrm{d}_{001}$ после прокаливания при $550^{\circ} \mathrm{C}$, зависит от количества алюминия, введенного в глину при пилларировании, степени кристалличности исходной глины и ее химического состава. Было установлено, что температура прокаливания в исследованном диапазоне влияла на удельную поверхность и объем микропор пилларированных образцов. Они отметили некоторую структурную деградацию пилларированных глин, которая выражалась в снижении значений удельной поверхности и объемов микропор после откачки при $400^{\circ} \mathrm{C}$. Адсорбция газов, таких, как $\mathrm{N}_{2}, \mathrm{O}_{2}, \mathrm{Ar}$ и $\mathrm{CO}_{2}$, на пилларированных глинах исследована в ряде работ [13-17].

В настоящее время в промышленном масштабе разрабатывается Таганское месторождение бентонитовых глин (Республика Казахстан), в которых содержание монтмориллонита составляет более $90 \%$ (в качестве незначительной примеси зафиксированы только каолинит и $\alpha$-кварц) [18]. Исследование морфологии частиц природных Таганских монтмориллонитов методом ПЭМ высокого разрешения показало, что кальциевая форма монтмориллонита представляет собой скопление агрегатов из равномерных тонкодисперсных чешуйчатых частиц, частицы натриевой формы имеют удлиненную брусковидную форму. Различие морфологических форм обусловлено строением октаэдрического слоя и содержанием в нем катионов $\mathrm{Fe}^{3+}$ и $\mathrm{Mg}^{2+}$.

В работе [19] приведены результаты модифицирования монтмориллонитовой глины Таганского месторождения для получения адсорбента, обладающего селективностью в отношении аргона и предназначенного для удаления аргона из смеси с кислородом. Целью исследования было выделение значимых факторов при модифицировании, влияющих на коэффициент разделения аргон-кислород и определение оптимальных условий модифицирования глины в диапазоне исследования. Было установлено, что одним из значимых факторов, влияющих на величину коэффициента разделения смеси аргон-кислород, является температура прокаливания образцов после их формования. Настоящая работа посвящена исследованию влияния температуры прокаливания пилларированной алюминием монтмориллонитовой глины Таганского месторождения на ее адсорбционные свойства по аргону и кислороду.

\section{Эксперимент}

В качестве исходного материала использовалась глина Таганского месторождения (Республика Казахстан) с содержанием монтмориллонита 90-98\% (предостав-

Иванова и др. / Сорбционные и хроматографические процессы. 2018. Т. 18. № 1 
ленная ООО «Алтайская сырьевая компания»), образец горизонта № 3, из которого была отсеяна фракция частиц 0.25-0.5 мм.

Использованная нами методика пилларирования глин подробно описана в [20]. Условия модифицирования глины: соотношение $\mathrm{Al}^{3+} / \mathrm{OH}^{-}$1:2.4, температура ионного обмена $25^{\circ} \mathrm{C}$, температура сушки $85^{\circ} \mathrm{C}$, температура прокаливания 300$600^{\circ} \mathrm{C}$.

В процессе приготовления модифицирующего раствора исходный водный раствор $0.2 \mathrm{M} \mathrm{AlCl}_{3}$ подвергался гидролизу путём капельного введения $0.2 \mathrm{M} \mathrm{NaOH}$ до соотношения 1:2.4. Гидролиз проводили при $60^{\circ} \mathrm{C}$. В процессе прибавления щёлочи раствор интенсивно перемешивали для предотвращения локальных пересыщений. Среднее время гидролиза составило 2-2.5 ч. Полученный раствор подвергали старению в течение 7 сут. Для ионного обмена исследуемую глину смешивали с модифицирующим раствором и интенсивно перемешивали в течение 4 ч при $25^{\circ} \mathrm{C}$. В дальнейшем, образцы оставляли под слоем модифицирующего раствора на 2 ч, после чего промывали дистиллированной водой и подвергали сушке. Сушку образцов осуществляли в сушильном шкафу при $85^{\circ} \mathrm{C}$ до полного испарения влаги.

Таблетирование образцов осуществляли без связующего методом сухого формования. Таблетки глины были получены с помощью гидравлического пресca Crush IR производства фирмы PTKE Technologies при давлении 780 кг. Полученные в процессе формования таблетки дробили на частицы, отбирали фракцию 1.0-2.0 мм.

Прокаливание проводили в атмосфере воздуха при $300-600^{\circ} \mathrm{C}$. Нагрев осуществляли со скоростью $5 \%$ мин, время выдержки - 2 ч.

Элементный состав образцов определяли рентгенофлуоресцентным методом с помощью приставки X-MAX INCA ENERGY (Oxford Instruments, Великобритания) к электронному микроскопу JEOL JSM-6510 LV (JEOL, Япония) в Центре коллективного пользования имени Д.И. Менделеева.

Для определения структурно-энергетических характеристик образцов пилларированной глины снимали изотермы адсорбции азота при $77 \mathrm{~K}$ на объемной установке Nova 1200e (Quantachrome, США). Перед измерением изотерм проводили дегазацию образцов при $300^{\circ} \mathrm{C}$ и остаточном давлении $10^{-3}$ мм рт. ст. в течение 4 ч.

Удельную поверхность $\left(S_{\text {уд }}\right)$ образцов рассчитывали по уравнению БЭТ [21]:

$$
a=\frac{a_{M} \cdot C \cdot p / p_{s}}{\left(1-p / p_{s}\right)\left[1+(C-1) p / p_{s}\right]},
$$

где $a$ - равновесная величина адсорбции, $a_{\mathrm{M}}$ - емкость монослоя на поверхности сорбента, $p / p_{s}$ - отношение давления системы к давлению конденсации, $C$ отношение констант адсорбционного равновесия первого слоя и конденсации пара.

Объем адсорбционного пространства микропор и характеристическую энергию адсорбции ( $W_{0}$ и $\left.E_{0}\right)$ рассчитывали по уравнению Дубинина-Радушкевича [21]:

$$
a / a_{0}=\exp \left[-\left(A / \beta E_{0}\right)^{2}\right]
$$

где $a$ - равновесная величина адсорбции, $a_{0}$ - предельная величина адсорбции в

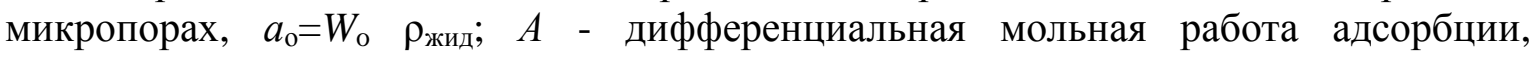
$A=\Delta G=R T \ln p_{s} / p ; E_{0}$ - характеристическая энергия адсорбции стандартного пара, $\beta$ коэффициент подобия, выражающий отношение характеристических энергий адсорбции стандартного и рассматриваемого паров. Для стандартного пара азота

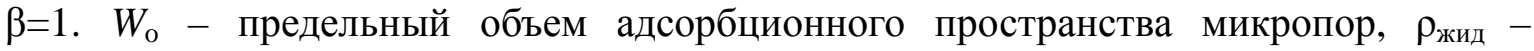
плотность жидкого адсорбата (азота).

Суммарный сорбционный объем мезо- и микропор $\left(V_{\mathrm{s}}\right)$ определяли по изотерме адсорбции азота при значении относительного давления, равном 0,995. 
Для проведения термогравиметрического анализа образцы исходной глины и образцы Al-PILC, прокаленные после формования при 300-600 ${ }^{\circ}$, предварительно насыщали в эксикаторе при комнатной температуре парами воды до состояния равновесия. Термогравиметрический анализ полученных образцов в среде аргона проводили на термоанализаторе SDT Q600 (TA Instruments, США), позволяющем одновременно регистрировать изменения массы образца (термогравиметрический анализ, ТГА) и процессы, сопровождающиеся выделением или поглощением тепла (дифференциальная сканирующая калориметрия, ДСК). Для измерения использовали корундовый тигель. Нагревание образцов проводили от комнатной температуры $\left(22^{\circ} \mathrm{C}\right)$ до $800^{\circ} \mathrm{C}$ в потоке аргона со скоростью 5 \%мин. Точность определения массы составляла 0.1 мкг, температуры $-0.001^{\circ} \mathrm{C}$. Обработку полученных дериватограмм проводили с помощью программы TA Universal Analysis.

Дериватограммы при нагревании образцов в воздушной среде снимали на системе термического анализа "Mettler Toledo-Star" (Швейцария), состоящей из дифференциального сканирующего калориметра с модулями термогравиметрического, дифференциального термического и термомеханического анализа. Нагревание образцов проводили от 20 до $750^{\circ} \mathrm{C}$ со скоростью 5 \%мин.

Равновесные емкости образцов по кислороду и аргону были определены на основании кинетических кривых адсорбции этих газов при $25^{\circ} \mathrm{C}$ и атмосферном давлении, снятых на волюмометрической установке. Относительная погрешность измерения составляла 5\%. Значения коэффициента разделения были рассчитаны как соотношение равновесных емкостей аргона и кислорода.

\section{Обсуждение результатов}

Элементный анализ модифицированных образцов Al-PILC, полученных при разных температурах прокаливания, приведен в табл.1.

Таблица 1. Элементный состав образцов Al-PILC

\begin{tabular}{|c|c|c|c|c|c|c|c|c|c|c|c|}
\hline \multirow{2}{*}{ № } & \multirow{2}{*}{$\begin{array}{c}\text { Температура про- } \\
\text { каливания, }{ }^{\circ} \mathrm{C}\end{array}$} & $\mathrm{O}$ & $\mathrm{Na}$ & $\mathrm{Mg}$ & $\mathrm{Al}$ & $\mathrm{Si}$ & $\mathrm{Ti}$ & $\mathrm{Fe}$ & $\mathrm{Ca}$ & $S$ & $\mathrm{Cl}$ \\
\hline & & \multicolumn{10}{|c|}{ Содержание элемента, мас.\% } \\
\hline $\begin{array}{l}\text { Глина } \\
\text { исх. }\end{array}$ & - & 59.24 & 0.52 & 1.60 & 9.96 & 23.98 & 0.36 & 3.80 & 0.36 & 0.03 & 0.15 \\
\hline 1 & 300 & 61.25 & 0.04 & 1.48 & 11.00 & 22.62 & 0.30 & 3.32 & - & - & - \\
\hline 2 & 350 & 60.50 & 0.04 & 1.48 & 11.23 & 22.95 & 0.31 & 3.49 & - & - & - \\
\hline 3 & 400 & 60.86 & 0.17 & 1.46 & 11.39 & 22.72 & 0.29 & 3.12 & - & - & - \\
\hline 4 & 450 & 60.97 & 0.09 & 1.47 & 11.26 & 22.77 & 0.30 & 3.14 & - & - & - \\
\hline 5 & 500 & 60.68 & 0.06 & 1.50 & 11.48 & 23.12 & 0.27 & 2.88 & - & - & - \\
\hline 6 & 550 & 63.95 & 0.06 & 1.46 & 10.59 & 21.53 & 0.21 & 2.21 & - & - & - \\
\hline 7 & 600 & 60.12 & - & 1.60 & 11.62 & 23.37 & 0.25 & 3.04 & - & - & - \\
\hline
\end{tabular}

Как следует из табл. 1, содержание алюминия во всех образцах Al-PILC увеличилось по сравнению с исходной глиной, содержание кремния уменьшилось, содержание катионов натрия существенно снизилось, кальций полностью отсутствовал.

Изотермы адсорбции азота при 77К на образцах Al-PILC приведены на рис. 1. Рассчитанные на основании изотерм адсорбции азота при 77К структурноэнергетические характеристики образцов Al-PILC представлены в табл. 2. 


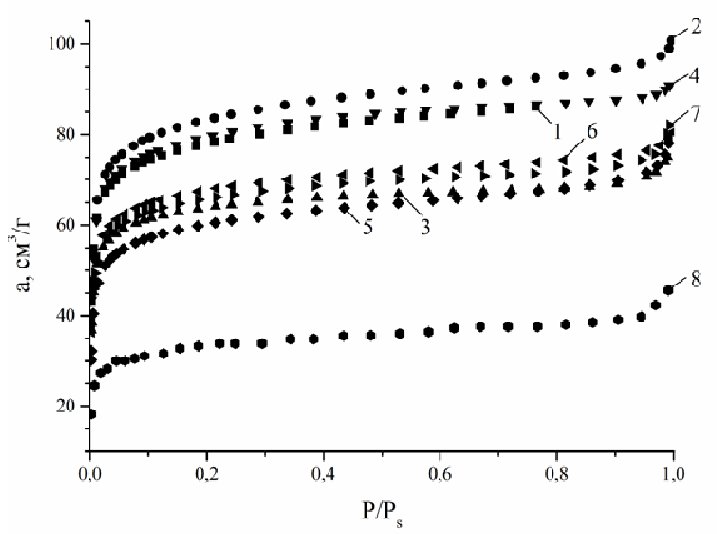

Рис. 1. Изотермы адсорбции азота при 77К на исходной глине и образцах Al-PILC, прокаленных при: $1-300^{\circ} \mathrm{C} ; 2-350^{\circ} \mathrm{C} ; 3-400^{\circ} \mathrm{C} ; 4-450^{\circ} \mathrm{C} ; 5-500^{\circ} \mathrm{C}$; $6-550^{\circ} \mathrm{C} ; 7-600^{\circ} \mathrm{C} ; 8-$ исходная глина.

Таблица 2. Структурно-энергетические характеристики образцов Al-PILC

\begin{tabular}{|c|c|c|c|c|c|}
\hline № образца & $\begin{array}{c}\text { Температура прокали- } \\
\text { вания, }{ }^{\circ} \mathrm{C}\end{array}$ & $S_{\text {уд }}, \mathrm{m}^{2} / \Gamma$ & $\begin{array}{c}W_{0}, \\
\mathrm{~cm}^{3} / \Gamma\end{array}$ & $\begin{array}{c}E_{0}, \\
\text { кДж/моль }\end{array}$ & $\begin{array}{c}V_{\mathrm{s}}, \\
\mathrm{cm}^{3} / \Gamma\end{array}$ \\
\hline $\begin{array}{c}\text { Исходная } \\
\text { глина }\end{array}$ & - & 77.5 & 0.04 & 12.4 & - \\
\hline 1 & 300 & 246.0 & 0.12 & 14.5 & 0.14 \\
\hline 2 & 350 & 264.0 & 0.13 & 14.0 & 0.16 \\
\hline 3 & 400 & 200.0 & 0.10 & 14.7 & 0.12 \\
\hline 4 & 450 & 251.0 & 0.13 & 13.7 & 0.14 \\
\hline 5 & 500 & 190.0 & 0.09 & 13.7 & 0.12 \\
\hline 6 & 550 & 235.8 & 0.12 & 13.0 & 0.15 \\
\hline 7 & 600 & 205.2 & 0.10 & 14.2 & 0.13 \\
\hline
\end{tabular}

Как следует из табл. 2, повышение температуры прокаливания в исследованном диапазоне слабо влияет на структурно-энергетические характеристики образцов Al-PILC. Тем не менее, тенденция к снижению величин $S_{\text {уд }}, W_{0}$ и $V_{\mathrm{s}}$ с ростом температуры прокаливания образцов прослеживается, что согласуется с данными для пилларированных монтмориллонитов, приведенными в работах $[7,17]$. Наименьшие значения характеристической энергии адсорбции азота зафиксированы у образцов, прокаленных при $450-550^{\circ} \mathrm{C}$.

Термогравиметрический анализ образцов, предварительно насыщенных влагой до равновесия в эксикаторе, проводили в среде аргона. На рис. 2, в качестве примера, представлены дериватограммы образцов исходной глины и Al-PILC, прокаленных при 300 и $600^{\circ} \mathrm{C}$ (образцы № 1 и № 7).

На кривых ДСК видны три эндопика с температурами минимумов 40.93 и 166.07 и $~ 350^{\circ} \mathrm{C}$ для исходной глины (рис. 2 a); $42.53,165.33$ и $359.3^{\circ} \mathrm{C}-$ для образца № 1 (рис. 2 б) и 50.58, 167.43 и $361.67^{\circ} \mathrm{C}$ - для образца № 7 (рис. 2 в). Значения температурных минимумов для других образцов пилларированной глины существенно не отличались от значений для образцов, приведенных на рисунках.

На кривых ТГА можно выделить две области изменения массы образцов: большие потери массы при нагревании вплоть до $300^{\circ} \mathrm{C}$, что объясняется десорбцией физически адсорбированной воды, и относительно небольшие потери массы в области $300-750^{\circ} \mathrm{C}$, что связывают с удалением воды с активных центров поверхности и дегидроксилированием образцов $[3,17,22]$. 
a)

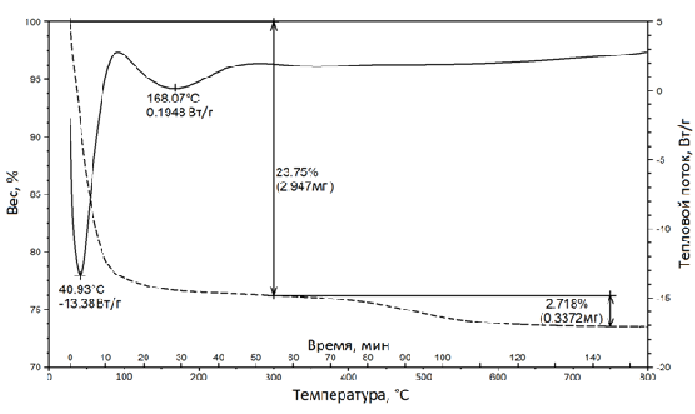

б)

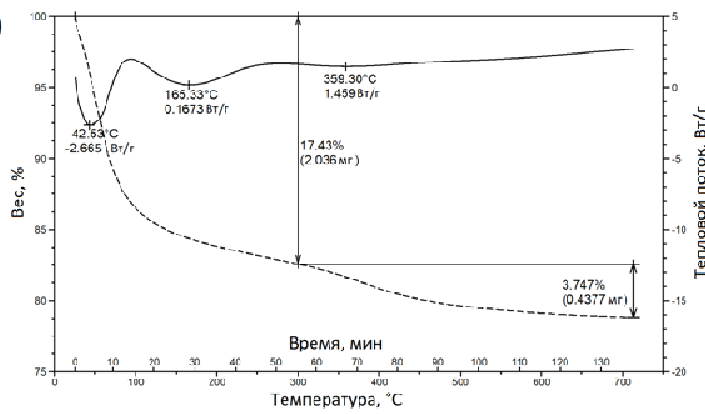

B)

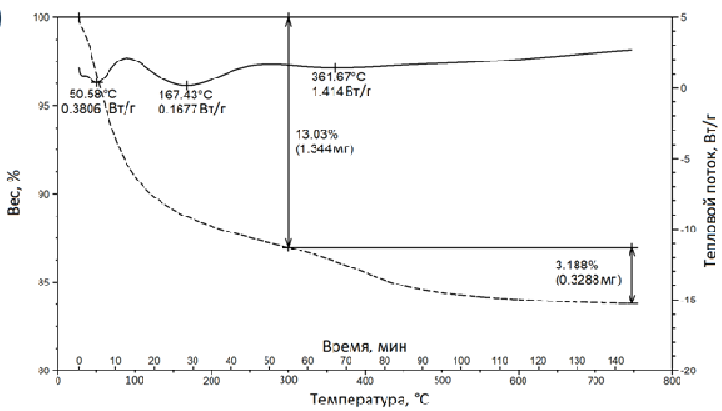

Рис. 2. Дериватограммы исходной и пилларированных глин в аргоне: a - исходная глина; б - №1 Al-PILC $\left(300^{\circ} \mathrm{C}\right)$; в - №7 Al-PILC $\left(600^{\circ} \mathrm{C}\right)$.

Согласно рис. 2 б, образец № 1 (Al-PILC, прокаленный при $300^{\circ} \mathrm{C}$ ) потерял $17.43 \%$ массы до $300^{\circ} \mathrm{C}$ и $3.75 \%$ - при нагревании в диапазоне $300-750^{\circ} \mathrm{C}$. Образец № 7, прокаленный при $600^{\circ} \mathrm{C}$ (рис. 2 в), потерял $13.03 \%$ массы до $300^{\circ} \mathrm{C}$ и $3.19 \%$ при нагревании в диапазоне $300-750^{\circ} \mathrm{C}$.

Результаты обработки дериватограмм, полученных для всех образцов, приведены в табл. 3. Цифры в скобках рядом с номером образца обозначают температуру прокаливания образца после формования.

Таблица 3. Потери массы образцов исходной глины и образцов Al-PILC при нагревании в аргоне и в воздушной среде

\begin{tabular}{|c|c|c|c|c|c|c|}
\hline \multirow{3}{*}{$\begin{array}{l}\text { № образ- } \\
\text { ца }\end{array}$} & \multicolumn{3}{|c|}{ Нагревание в аргоне } & \multicolumn{3}{|c|}{ Нагревание на воздухе } \\
\hline & \multicolumn{2}{|c|}{$\begin{array}{l}\text { Потеря массы при } \\
\text { нагревании, } \Delta m, \%\end{array}$} & \multirow{2}{*}{$\begin{array}{c}\text { Суммарная по- } \\
\text { теря массы, } \Delta \mathrm{m} \text {, } \\
\%\end{array}$} & \multicolumn{2}{|c|}{$\begin{array}{l}\text { Потеря массы при } \\
\text { нагревании, } \Delta m, \%\end{array}$} & \multirow{2}{*}{$\begin{array}{c}\text { Суммарная } \\
\text { потеря массы, } \\
\Delta \mathrm{m}, \%\end{array}$} \\
\hline & $\begin{array}{c}\text { до } \\
300^{\circ} \mathrm{C} \\
\end{array}$ & $\begin{array}{c}300- \\
750^{\circ} \mathrm{C} \\
\end{array}$ & & $\begin{array}{c}\text { до } \\
300^{\circ} \mathrm{C} \\
\end{array}$ & $\begin{array}{c}300- \\
750^{\circ} \mathrm{C} \\
\end{array}$ & \\
\hline исходная & 23.75 & 2.72 & 26.46 & 22.25 & 2.37 & 24.86 \\
\hline №1 (300) & 17.43 & 3.75 & 21.17 & 15.76 & 3.93 & 19.69 \\
\hline №2 (350) & 17.04 & 4.05 & 21.09 & - & - & - \\
\hline №3 (400) & 16.64 & 3.77 & 20.20 & - & - & - \\
\hline №4 (450) & 16.65 & 3.62 & 20.26 & - & - & - \\
\hline №5 (500) & 15.65 & 3.41 & 19.06 & - & - & - \\
\hline №6 (550) & 14.07 & 3.17 & 17.24 & - & - & - \\
\hline №7 (600) & 13.03 & 3.19 & 16.22 & 12.29 & 2.91 & 15.20 \\
\hline
\end{tabular}

Наибольшую потерю массы наблюдали у исходного образца глины (26.46 \%), при этом: на первом участке при нагревании до $300^{\circ} \mathrm{C}-23.75 \%$ и в диапазоне от 300 до $750^{\circ} \mathrm{C}-2.72 \%$ (рис. 2 а). Как следует из результатов, основная потеря массы у образцов Al-PILC, также как у исходной глины, происходила при нагревании до $300^{\circ} \mathrm{C}$ 
Как видно из табл. 3, с увеличением температуры прокаливания образцов AlPILC происходило снижение потери массы при нагревании до $300^{\circ} \mathrm{C}$. В температурном диапазоне $300-750^{\circ} \mathrm{C}$ у образцов Al-PILC потери массы были больше, чем у исходной глины. Зависимость потери массы от температуры прокаливания образцов после формования проходит через максимум для образца, прокаленного при $350^{\circ} \mathrm{C}$. Суммарная потеря массы для всех образцов Al-PILC была меньше, чем у исходной глины, и снижалась с ростом температуры прокаливания, что говорит о возрастании гидрофобности пилларированных образцов при увеличении температуры прокаливания во время их модифицирования.

Дериватограммы при нагревании исходной глины и образцов Al-PILC в воздушной атмосфере при использовании прибора «Mettler Toledo-Star» (Швейцария) имели аналогичный вид. Результаты термогравиметрического анализа в воздушной среде для исходной глины и образцов № 1 (300) и № 7 (600) приведены в табл. 3.

При сопоставлении результатов, полученных с использованием разных аналитических систем, видно, что численные данные несколько отличаются, но общая тенденция в зависимости потери массы образцами исходной и пилларированных глин при нагревании сохраняется, вне зависимости от среды. В литературе описаны результаты термогравиметрического анализа монтмориллонитов различных месторождений, проведенного в воздушной среде [3,22] и в среде гелия [17].

На кривой дифференциально-термического анализа (ДТА) монтмориллонитовой глины выделяют следующие эндотермические эффекты. В области $100-170^{\circ} \mathrm{C}$ и далее вплоть до $300^{\circ} \mathrm{C}$ происходит интенсивное удаление адсорбированной воды. Потеря конституционной (гидроксильной) воды монтмориллонитом начинается при $500^{\circ} \mathrm{C}$ и заканчивается при $800 \pm 50^{\circ} \mathrm{C}$ с возникновением безводной модификации монтмориллонита [3]. Для монтмориллонитов с изоморфным замещением алюминия на $\mathrm{Fe}$ или $\mathrm{Mg}$ эта трансформация начинается при $450-500^{\circ} \mathrm{C}$ и заканчивается при $750^{\circ} \mathrm{C}[17,22]$. Удаление остаточной сорбированной воды и гидроксильной воды из кристаллической решетки монтмориллонита приводит к образованию точечных, а затем в результате спекания, прочных фазовых контактов между частицами, что ведет к снижению значений удельной поверхности. Образование нерасширяющихся пакетов при нагревании является также следствием миграции катионов в вакантные тетраэдрические позиции структуры или фиксации их в псевдогексагональных углублениях решетки [3].

Третья трансформация имеет место при $\sim 800^{\circ} \mathrm{C}$, этот эндопик приписывают

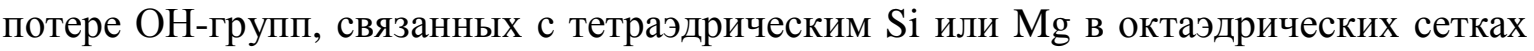
[17]. На кривых ДТА полное разрушение кристаллической решетки монтмориллонита, сопровождаемое перекристаллизацией, отмечается при $800-1000^{\circ} \mathrm{C}$. Реакции и процессы, протекающие в монтмориллонитах при нагревании, зависят от характера взаимной упорядоченности алюмосиликатных слоев, наличия в них отдельных дефектов и вида обменных катионов [3].

Как следует из представленных результатов, в интервале исследования с ростом температуры прокаливания образцов Al-PILC происходило снижение содержания адсорбционной и гидроксильной воды в образцах, т.е. развитие гидрофобности. Наибольшая потеря активных центров сорбции кислорода связана с удалением катионов металлов из межплоскостного зазора при пилларировании, а также с удалением ОН-групп во время прокаливания при 400-600 $\mathrm{C}$. Развитие гидрофобности с ростом температуры прокаливания пилларированного монтмориллонита авторы работы [7] объяснили также высвобождением протонов во время дегидроксилирования пилларов и их миграцией из межслоевого расстояния в октаэдрические сетки. 
Значения равновесных величин адсорбции кислорода и аргона (усредненные по данным трех измерений) и коэффициента разделения смеси аргон-кислород приведены в табл. 4. Как следует из результатов табл. 4, наибольшее значение коэффициента разделения наблюдали у образца Al-PILC, прокаленного при $550^{\circ} \mathrm{C}$. При сопоставлении данных табл. 2 и 4 также стоит отметить, что величина равновесной емкости по аргону имеет минимальное значение для образца, температура прокаливания которого была $400^{\circ} \mathrm{C}$, и максимальное значение - для образца с температурой прокаливания $550^{\circ} \mathrm{C}$, что коррелирует с наибольшим и наименьшим значениями характеристической энергии (14.7 и 13.0 кДж/моль, соответственно).

Таблица 4. Влияние температуры прокаливания образцов Al-PILC на коэффициент разделения смеси аргон-кислород

\begin{tabular}{|c|c|c|c|}
\hline \multirow{2}{*}{ № образца } & \multicolumn{2}{|c|}{ Равновесная адсорбция при $25^{\circ} \mathrm{C}$} & \multirow{2}{*}{$\begin{array}{c}\text { Коэффициент разделения } \\
\text { смеси Ar-О }\end{array}$} \\
\cline { 2 - 3 } & $\mathrm{O}_{2}$ & $\mathrm{Ar}$ & 1.3 \\
\hline №1 (300) & 3.33 & 4.34 & 1.0 \\
\hline №2 (350) & 4.08 & 3.97 & 0.8 \\
\hline №3 (400) & 4.12 & 3.16 & 1.0 \\
\hline №4 (450) & 4.20 & 4.17 & 1.2 \\
\hline №5 (500) & 4.19 & 5.09 & 1.5 \\
\hline №6 (550) & 3.85 & 5.74 & 1.2 \\
\hline №7 (600) & 3.39 & 4.10 & s. $^{3} / \Gamma$ \\
\hline
\end{tabular}

Эксперименты показали, что в широком диапазоне изменения значений температуры прокаливания коэффициент разделения смеси аргон-кислород изменялся слабо. Адсорбция кислорода была максимальна у образцов, прокаленных при 350$500^{\circ} \mathrm{C}$. При дальнейшем повышении температуры прокаливания адсорбция кислорода несколько снижалась. При температурах $>550^{\circ} \mathrm{C}$ происходило одновременное снижение адсорбции аргона, которое, возможно, связано с изменением текстурных характеристик, но очевидной связи не просматривается.

Эксперименты показали, что переменный состав природного монтмориллонита приводит к плохой воспроизводимости результатов по определению свойств получаемых материалов и, в силу этого, к трудности создания технологии получения адсорбентов со стабильными свойствами для селективной адсорбции аргона. Практическое применение адсорбентов, созданных на основе пилларированных глин, для разделения газовых смесей, вероятно, проблематично из-за отсутствия источников чистой глины.

\section{Заключение}

На основе природного монтмориллонита были получены пилларированные глины с помощью ионного обмена с растворами основных солей алюминия и последующего прокаливания. Было исследовано влияние температуры прокаливания в диапазоне $300-600^{\circ} \mathrm{C}$ на текстурные характеристики и адсорбционную емкость пилларированной глины по аргону и кислороду. Проведен термогравиметрический анализ синтезированных образцов. Показано, что текстурные характеристики пилларированной глины и коэффициент разделения смеси аргон-кислород незначительно зависят от температуры прокаливания в исследованном диапазоне. Наибольшее значение коэффициента разделения смеси аргон-кислород наблюдали у образца AlPILC (№6), прокаленного при $550^{\circ} \mathrm{C}$. 
Авторы благодарят к.т.н. В.А. Дьяконова (ОАО «Композит») $u$ Кондакову Н.Н. (РХТУ им. Д.И. Менделеева) за выполненные ими термогравиметрические анализы образцов.

\section{Список литературы}

1. Тарасевич Ю.И. Поверхностные явления на дисперсных материалах. Киев. Наукова думка. 2011. $390 \mathrm{c.}$

2. Тарасевич Ю.И. Строение и химия поверхности слоистых силикатов. Киев. Наукова думка. 1988. 248 с.

3. Арипов Э.А., Агзамходжаев А.А. Активные центры монтмориллонита и хемосорбция. Ташкент. Фан. 1983. 164 с.

4. Кормош Е.В. Модифицирование монтмориллонитовых глин для комплексной сорбционной очистки сточных вод: Автореф. дис. канд. техн. наук. Белгород. 2009. 19 с.

5. Трофимова Ф.А. Структурное и кристаллохимическое технологического щелочноземельных обоснование модифицирования бентонитов и бентонитоподобных глин: Автореф. дис. канд. геолого-минерал. наук. М. 2006. 24 с.

6. Лазоренко Г.И. // Инженерный вестник Дона. 2011. Т. 18. № 4. С. 100-103.

7. Kloprogge J.T. // Journal of Porous Materials. 1998. Vol. 5. No 1.pp. 5-41.

8. Achma R.B. // Applied Catalysis A: General. 2008. Vol. 349. No 1. pp. 20-28.

9. Brindley G.W., Sempels R.E. // Clays and Clay Minerals. 1977. Vol. 12. No 3. pp. 229237.

10.Scnoonheydt R.A., van den Eynde G., Tubbax H. et al. // Clays and Clay Minerals. 1993. Vol. 41. No 5. pp. 598-607.

11.Scnoonheydt R.A., Leeman H., Scorpion A., Lenotte I. et al. // Clays and Clay Minerals. 1994. Vol. 42. No 5. pp. 518-525.

\section{References}

1. Tarasevich Yu.I. Poverkhnostnye yavleniya na dispersnykh materialakh, Kiev, Naukova dumka, 2011.390 p.

2. Tarasevich Yu.I. Stroenie i khimiya poverkhnosti sloistykh silikatov. Kiev, Naukova dumka, 1988. $248 \mathrm{p}$.

3. Aripov E.A., Agzamkhodzhaev A.A., Aktivnye tsentry montmorillonita i khemosorbtsiya, Tashkent, Fan, 1983. 164 p.

4. Kormosh E.V. Modifitsirovanie montmorillonitovykh glin dlya kompleksnoi sorbtsion-
12.Тимофеева М.Н., Ханкасаева С.Ц. // Кинетика и катализ. 2009. Т. 50. № 1. С. 6371.

13.Yang R.T., Baksh M.S.A. // AIChE Journal. 1991. Vol. 37. No 5. pp. 679-686.

14.Zhu H., Lu G.// J. of Porous Materials. 1998. Vol. 5. No 3. pp. 227-239.

15. Molinard A., Vansant E.E.// Adsorption. 1995. Vol. 1. No 1. pp. 49-59.

16.Zhu H.Y., Vansant E.F.// J. of Porous Materials. 1995. V. 2. № 1, p. 107-113.

17.de Carvalho M. B., Pires J., Carvalho A. P.// Microporous Materials. 1996. Vol. 6. No 2. pp. 65-77.

18.Финевич В.П. // Российский химический журнал (ЖРХО им. Д.И.Менделеева). 2007. T. 51. № 4. C. 69-75.

19. Иванова Е.Н., Бурмистрова Н. Н., Алехина М. Б., Дудоладов А.О. и др. // Сорбичионные и хроматографические прочессы. 2017. T. 17. № 4. C. 657-666.

20.Конькова Т.В. Алехина М.Б., Рысев А.П., Садыков Т.Ф. и др. // Перспективные материальь. 2013. № 2. С. 58-63.

21.Кельцев Н.В. Основы адсорбционной техники. М. Химия. 1984. 592 с.

22.Маслова М.Д. Влияние ионного состава почвенного раствора на изменение коллоидно-химических свойств почв. Дис. канд. биол. наук. М. РГАУ - МСХА имени К.А. Тимирязева, 2015. 184 с.

noi ochistki stochnykh vod: Avtoref. dis. kand. tekhn. Nauk, Belgorod, 2009, 19 p.

5. Trofimova F.A. Strukturnoe i kristallokhimicheskoe obosnovanie tekhnologicheskogo modifitsirovaniya shchelochnozemel'nykh bentonitov i bentonitopodobnykh glin: Avtoref. dis. kand. geologo-mineral. nauk. M., 2006, 24 p.

6. Lazorenko G.I., Inzhenernyi vestnik Dona, 2011, Vol. 18, No 4, pp. 100-103.

7. Kloprogge J.T., Journal of Porous Materials, 1998, Vol. 5, No. 1, pp. 5-41. 
8. Achma R.B., Applied Catalysis A: General., 2008, Vol. 349, No 1, pp. 20-28.

9. Brindley G.W., Sempels R.E., Clays and Clay Minerals, 1977, Vol. 12, No 3, pp. 229237.

10. Scnoonheydt R.A., van den Eynde G., Tubbax H. et al., Clays and Clay Minerals, 1993, Vol. 41, No 5, pp. 598-607.

11. Scnoonheydt R.A., Leeman H., Scorpion A., Lenotte I. et al., Clays and Clay Minerals, 1994, Vol. 42, No 5, pp. 518-525.

12. Timofeeva M.N., Khankasaeva S.Ts., Kinetika i kataliz, 2009, Vol. 50, No 1, pp. 6371.

13. Yang R.T., Baksh M.S.A., AIChE Journal, 1991, Vol. 37, No 5, pp. 679-686.

14. Zhu H., Lu G., J. of Porous Materials, 1998, Vol. 5, No 3, pp. 227-239.

15. Molinard A., Vansant E.E., Adsorption, 1995, Vol. 1, No 1, pp. 49-59.

Иванова Екатерина Николаевна - аспирант 4-ого года обучения факультета Технологии неорганических веществ и высокотемпературных материалов Российского химикотехнологического университета имени Д.И. Менделеева, Москва

Бурмистрова Наталья Николаевна - магистрант 2-ого года обучения факультета Технологии неорганических веществ и высокотемпературных материалов Российского химикотехнологического университета имени Д.И. Менделеева, Москва

Алехина Марина Борисовна - д.х.н., доцент, профессор кафедры Технологии неорганических веществ и электрохимических процессов Российского химико-технологического университета имени Д.И. Менделеева, Москва

Дудоладов Александр Олегович - аспирант 1-ого года обучения факультета Технологии неорганических веществ и высокотемпературных материалов Российского химикотехнологического университета имени Д.И. Менделеева, Москва
16. Zhu H.Y., Vansant E.F., J. of Porous Materials, 1995, Vol. 2, No 1, pp. 107-113.

17. de Carvalho M. B., Pires J., Carvalho A.P., Microporous Materials, 1996, Vol. 6, No 2, pp. 65-77.

18. Finevich V.P., Rossiiskii khuimicheskii zhurnal (ZhRKhO im. D.I.Mendeleeva), 2007, Vol. 51, No 4, pp. 69-75.

19. Ivanova E.N., Burmistrova N. N., Alekhina M. B., Dudoladov A.O. et al., Sorbtsionnye $i$ khromatograficheskie protsessy, 2017, Vol. 17, No 4, pp. 657-666.

20. Kon'kova T.V. Alekhina M.B., Rysev A.P., Sadykov T.F. et al., Perspektivnye materialy, 2013, No 2, pp. 58-63.

21. Kel'cev N.V., Osnovy adsorbcionnoj tehniki. M., Himija, 1984. 592 p.

22. Maslova M. D. Vliyanie ionnogo sostava pochvennogo rastvora na izmenenie kolloidnokhimicheskikh svoistv pochv. Dic. kand. biol. nauk. M, RGAU, 184 p.

Ivanova Ekaterina N. - the postgraduate student, department of technology of inorganic substances and electrochemical processes, D.I. Mendeleyev University of Chemical Technology of Russia, Moscow, E-mail: ivkatushka@gmail.com.

Burmistrova Natalya N. - past master, department of technology of inorganic substances and electrochemical processes, D.I. Mendeleyev University of Chemical Technology of Russia, Moscow, E-mail: Burmistrova.natasha1994@yandex.ru.

Alekhina Marina B. - doctor of chemical Sciences, associate prof., department of technology of inorganic substances and electrochemical processes, D.I. Mendeleyev University of Chemical Technology of Russia, Moscow, E-mail: lekhina@yandex.ru.

Dudoladov Alexander O. - the postgraduate student, department of technology of inorganic substances and electrochemical processes, D.I. Mendeleyev University of Chemical Technology of Russia, Moscow, E-mail: nerfangorn@gmail.com. 